\title{
DESIGN AND DOUBLE BIND COMMUNICATION IN PUBLIC SERVICES-THE MODEL OF LOGICAL PARADOXES
}

\author{
Linda BLAASV/Er ${ }^{1}$ and Tore GULDEN ${ }^{2}$ \\ ${ }^{1}$ The Norwegian Labour and Welfare Administration \\ 2Oslo Metropolitan University
}

\begin{abstract}
This article introduces the understanding of double bind communication from cybernetic theory and describes how a synthesized model of logical paradoxes can serve as a means for systems analysis of double bind communication inherent in the relationship between clients and service providers. The study is oriented in the context of the Norwegian Labour and Welfare Administration (NAV). Double bind can be described as communication that is paradoxical in contexts where, for example, the client, in this study the citizen, seeking help in difficult life situations, encounters dimensions of being disciplined and helped as two facets of a conversation with the service provider, in this study a public servant representing a welfare provider.

We have explored communication sequences in citizen-public servant conversations in relation to cybernetic theory and Bateson to understand and design services that meet users with double bind communication in welfare services in particular and service design in general. This is to design a mutually trustworthy relationship between the citizen and welfare provider. It is suggested that the model of logical paradoxes synthesized in this research should be introduced to design students. This will enable a wider understanding of double bind functioning and thus create a method to design for situations where double bind communication is detected or unavoidable.
\end{abstract}

Keywords: Systemic design, cybernetic theory, double bind, design method, public services, sustainable welfare system

\section{SYSTEMS ANALYSIS OF DOUBLE BIND COMMUNICATION IN THE CONTEXT OF WELFARE SYSTEMS}

Designers with various backgrounds from product design, design for user experience, service design, design research and systemic design operate in complex contexts in their practice. A typical example of such a complex situation is the creation of fruitful communication sequences between the Norwegian Labour and Welfare Administration (NAV) represented by a public servant and the citizen as part of the total welfare service system. In today's system, there are existent communication sequences where the public servant must discipline and support the citizen in the same conversation. An example of this is when a public servant, who is instructed to motivate the citizen to take part in an activity-a course on how to apply for a job or write a resume, a motivation course, an education programme, etc.- -is also required to discipline the citizen if he or she does not take part in the activity agreed upon. On one side, the organization is set up to support all citizens to be able to live independent lives. The system that is built to effectuate such support consists of offerings such as free education, monetary benefits, and support for living accommodations. However, to receive such support from NAV, citizens who may be in a burdensome situation due to sudden change in life through major events, such as illness, depression, or loss of job, must comply and perform in accordance with the demands listed as prerequisites. These double bind communication situations in NAV occur due to internal organization and the internal distribution of tasks and operations. Another reason double bind communication situation occur is the enforcement of national laws and regulations as criteria to receive welfare support. The principle that has emerged out of this organizational structure can be explained as follows: aid is given if the citizen performs, and this represents a paradox since the citizen approached NAV in the first place because he 
or she could not perform. Paradoxes, such as the one described, referred to as double bind in systems theory [1], øllø $\mathrm{m} 0$, are not unusual in the public services sector. Interestingly, most designers that work to handle such complex situations lack knowledge about double bind communication situations and thus miss out on the disclosure and ability to handle them.

\subsection{Double bind}

Double bind is a term coined by Gregory Bateson [2] and is briefly described by his daughter Mary Catherine Bateson as "a communication function that conveys contradicting messages at different logical levels" [1]. She further elaborated on the double bind as "an abstract pattern of relationships that might show up in particular exchanges, but these always depended on the broader context." She then refers to her father's example of such a situation, which he described on the basis of an observation of "a young man who had been in hospital and was somewhat recovered from an acute schizophrenic episode when he was visited by his mother." Gregory's account of the event: "He was glad to see her and impulsively put his arm around her shoulders, whereupon she stiffened. He withdrew his arm, and she asked, 'Don't you love me anymore?' He then blushed, and she said, 'Dear, you must not be so easily embarrassed and afraid of your feelings." "[1]. In this sequence, the young man seeks to communicate his affection for his mother, which is rejected. His subsequent need for confirmation of his mothers' love for him is punished and serves as a supplementary rejection. The failure of his mother to communicate her love for him is laid on him. As M.C. Bateson stated, "The double bind is created in interaction between two or more parties or entities (I am deliberately avoiding saying 'persons' here, which is the usual phrasing - really we are dealing with parts of some larger whole) in a significant non-transient relationship that continues over an extended period, with the same pattern repeated again and again. In this pattern there is a contradiction between messages at different logical levels: a primary injunction and a second injunction at another level affecting the interpretation of the first. There is some real emotional danger or threat in this situation, no possibility of withdrawing from it, and no possibility of naming the problem"[1]. Double bind is not a countable measure; however, it describes a phenomenon destructive to communication and functioning. Hence, a service that represents double bind functioning may be destructive and work counter to the goal with the service [3] and, by extension, the policy intended. Double bind may not be possible to prevent, but we can be aware of the phenomenon when designing welfare services.

\subsection{Double bind situations in welfare services}

Citizens and public servants behave and adjust in accordance with the systems that enable encounters between them. Both ends of the communication know that one must behave in a specific way to achieve desired outcomes. Citizens adjust to monetary and social support systems that shape their behaviour. The public servant, being on the other side, behaves in line with the power structures, hierarchy, administrational system, execution of laws and regulations and so forth. The intention of a welfare system is to arrange for the citizens to receive various types of benefits or support during a troublesome period. However, the communication systems may work to the disadvantage of both citizens and welfare systems because the relationship represents different perspectives and goals. Accordingly, the nature of the relationships may hinder the welfare provider and the functioning of the programme itself when the communication function hinders or demotivates the initiative from benefiting the citizen who is in need of support. Double bind or double communication occurs in various systems, as for example M.C. Bateson pointed out: "Living in an individualistic Western society, we are double bound by being told we are free and by being subject to a large number of social controls that make us unfree, we are unwilling to analyse the contradiction between our purposes and our survival (as individuals or as a species) or the contradiction between being organisms that necessarily must die and being convinced of the need to stay alive" [1]. Thus, the understanding of being free for a child within a family structure may represent such double bind messages: You are free but also controlled by the same parents that say you are free. In educational systems, pupils and students are encouraged and evaluated by the same system and in design education, particularly educators who typically make demands of students using messages such as "You must be free, you must make your own choices." As Bateson points out, "There is a contradiction: If you must be free, then you are not free" [1]. Based on the latter example of a paradox in logic, we developed a model that describes double bind communication between citizens and welfare providers as a process of developing a design method that stimulates awareness and understanding at different levels of complexity for the designer. 
Message

You have to work to

receive welfare support
Contradiction in message

If you can work you don't

need welfare support

\section{Figure 1. Example of double bind communication in the context of welfare service systems}

The intention with the examples in the boxes that illustrate contradiction in messages typical of NAV and the welfare system context is to exemplify and contextualize double bind communication for design students that want to learn about public services and designers in organizations such as NAV. To prepare design students to work within such complex situations as described, systemic design education has emerged.

\section{UNDERSTANDING COMMUNICATION SYSTEMS IN SYSTEMIC DESIGN}

Systemic design is a combination of design practice and systems theory. Systems represent exceedingly complex networks of relations in eco-systems, environments, society, organizations, services, and social systems, including circumstances i.e., and cannot be approached with standard design or engineering methods [4]. The systemic design methods that enable designers to explore systems, environments, societies, organizations and public services are, therefore, linked to complexity and systems theory. Systemic design thus serves as a methodology for design in such complexity. By systemic design practice and research, the method of GIGA mapping has emerged. GIGA mapping is a method that designers use in cooperation with stakeholders, clients and users i.e., to create an overview of situations that make the origin for future designs by visualization. GIGA maps thus often serve as a platform to visualize all systems within the imagined scope of a project. Visualizations of main systems connected systems, their functioning, relations and the structure the systems depend on and represent thus make up a total picture of the complexity of the situation at hand. The GIGA map functions thus as a holistic approach by visualizing the whole report, which in turn invites all participants to see all pages of the report simultaneously and thus work, synthesize, connect, react and add i.e., to the content of the work. Visualizing all the empirical data into one or more GIGA maps does not, however, ensure quality. The designer must have methods to analyse the complexity of the data to reach new solutions by design. Knowledge about systems theory marks the origin for such analysis in systemic design that can inform the design team about the existing systems at hand, what structure they depend on and the organization of these self-producing qualities, systems functioning and related networks of relations, reinforcing and balancing feedback loops and strong or weak connections i.e. In systemic design, hindrances or so-called problems caused by, for example, programme errors or user experience design that stimulate misunderstanding receive little attention since they solely represent structural dimensions and thus have a minimal potential for systemic change. The emphasis in systemic design lies within system functioning, system malfunctioning, connected systems or missing connected systems. For example: "Missing feedback is one of the most common causes of system malfunction. Adding or restoring information can be a powerful intervention, usually much easier and cheaper than rebuilding physical infrastructure. ... That's a perverse feedback, a positive loop that leads to collapse" [5]. Accordingly, we have directed our research to produce insight about communication and double bind communication in complex systems in particular, the discussion about how these dimensions can lead to the emergence of a discursive design method that stimulates design students and designers to seek understanding rather than imitate problem solving, and a discussion about facets of double bind in service design.

\subsection{Designing communication systems with awareness of double bind functioning}

Bateson stated: "It is rather generally believed that 'causes' or 'reasons' for alcoholism are to be looked for in the sober life of the alcoholic" [2]. By this formulation, he suggested that we all seem to research what others do and within the same logic. This way of thinking, which involves exploring the other end of a situation, is what is referred to as "negative explanation" or cybernetic analysis [2]. To develop a method that stimulates designers to research another logic and stimulates discussions about logic in systems themselves, we used negative explanation as a process. By combining the negative explanation 
of being or feeling free, which originates in Bateson's example of double bind and freedom and double bind communication, we synthesized a method for design discussions and exploration. Free can be analysed within the range of free to not free. That is, we suggest that designers seek understanding about free by examining what is not free. The different levels of communication that are represented in a public organization, company i.e., may represent different logics between these two ends.

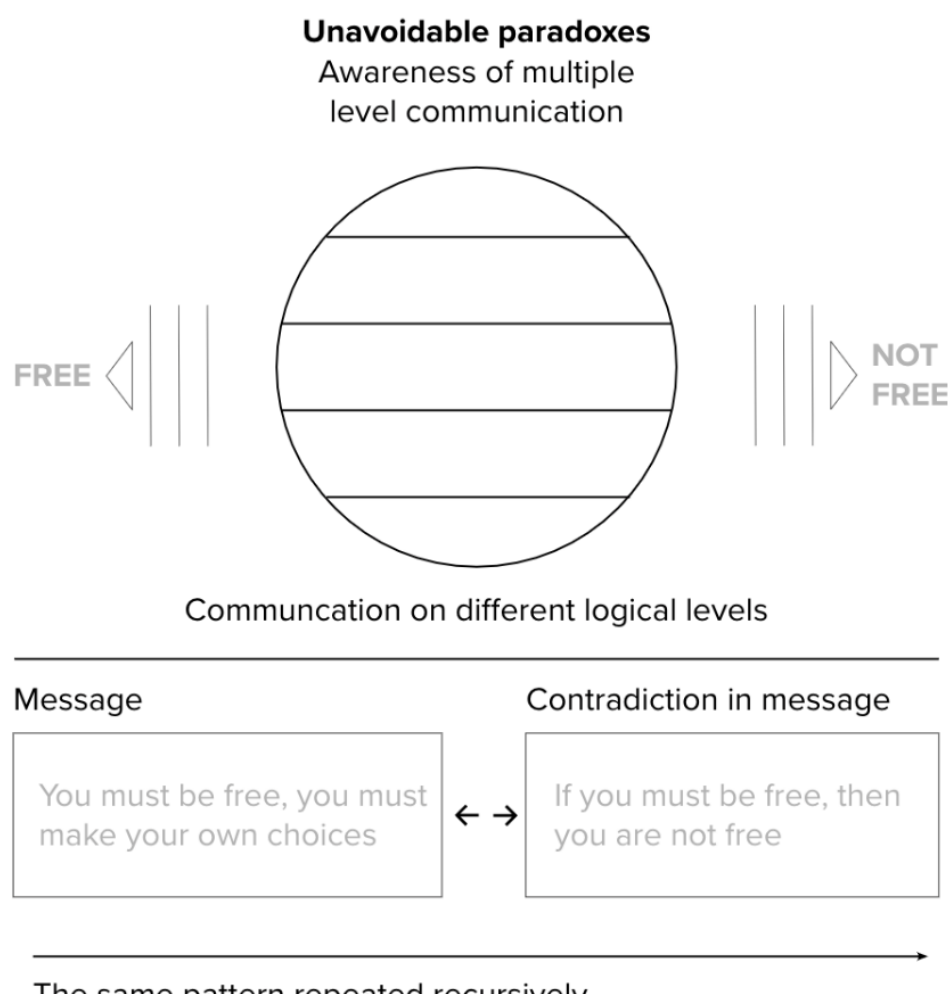

The same pattern repeated recursively

THE MODEL OF THE LOGIC PARADOXES

Figure 2. The model enables designers to identify similar logical paradoxes in the contexts they practice and to formulate the specifics of such contradiction in messages in the project

\subsection{User-orientation and systemic insight}

Service designers working with user-oriented processes typically emphasize user satisfaction to provide good user experiences between the service user and the service provider and the value exchange between them. However, the immediate gratification of such experiences does not necessarily equal quality in service functioning over time. Hence, service design could benefit from processes that stimulate thinking about the experience of the citizen as a whole by, for example, exploring experience in relation to time. As an example, a tobacco-free city does not offer citizens immediate gratification, but it does when welfare is considered in the long run or as part of a whole.

Hence, service design methodology neglects a holistic perspective by the user-orientation, emphasizing the immediate experiences as a central method of services. That is, the methods lack thinking about forms of communication systems, overlapping dependent systems and thus the need for system insight and knowledge about the system characteristics, functioning and malfunctioning.

\subsection{About the method, the logical paradoxes}

The research describes various situations and kinds of functioning of double bind within NAV, involving phenomena and tensions in encounters between citizens and a welfare system and the functioning of double bind between systems in general. We have witnessed a need for a flexible and in-depth understanding of the system dynamics concept combined with the observing concepts from cybernetics to work for open-minded thinking processes for design students. As designers are increasingly involved in designing services for the public sector, a field of complexity, uncertainty and unknown unknowns, designers are expected to handle such uncertainty. Through this article, we seek to explore pedagogical 
methods to understand the systemic character of systems, which often have invisible elements, however concretely such elements, such as a communication system, can define the functioning of the system.

\subsection{What did we do?}

We used theory from cybernetic and system dynamics, the concept of double bind and Meadows 12 leverage points [5], to form the model of the logical paradoxes. The negative explanations that describe a phenomenon and the other end of a phenomenon (free-not free) represent the level of contradiction in a message/communication. To discuss the different levels of logic involved in creating paradoxical messages, we used Bateson's perspectives on communication as circuits of praxis (detailed descriptions of behaviour) [2] by visualizing the praxis of citizens forced to document their recurring misery over time in a conversation with NAV supervisors (that may create a thinking pattern in the citizen that can produce lost self-confidence, the opposite of the goal of the welfare system). We called these elements the message and the contradicting message in the model of logic paradoxes. The focus of the research was to include elements in the context of these messages to be able to understand the system from a holistic perspective and to grasp what type of dependencies lie within the system characteristic that allows for these double bind messages to endure. Systemic design requires an understanding of the relationships between elements in a system. The model encourages visualizing patterns of thought and communication to learn how a citizen receives a message and how a welfare system communicates a message. "Double bind is not something that happens to a mind but something that happens in a mind" [1].

\section{IMPLICATIONS FOR DESIGN}

The model of the logical paradoxes is a tool for design as inquiry towards understanding rather than for problem solving. It is a tool for investigating patterns in communication and encounters between citizens and public services to identify occurrences of double bind communication on different logical levels. It is thus a discursive tool for design thinking and learning about logical paradoxes inherent in our world and in services developed in a complex field and for experimenting through the design process with different models containing different stakeholders' perspectives and objectives. The model facilitates an exploration of the relationship between people and services through a communication lens on different logical levels to spark a reflection about communication systems, abstract immediate systems, physical structures, forced communication, absent communication and so forth. The model of the logical paradoxes may serve to elicit discussions about how we can design public services that provide a trustworthy relationship between citizens and the public sector that contains a minimum of double bind communication.

\section{DISCUSSION AND REFLECTION}

This research investigates how we can provide citizens with financial security as part of a service while also allowing the public servant to be a "good helper" who "pushes" when needed. That is opposed to today's situation where the public supervisor is forced to "discipline" the client because of a rigid system. It represents classic double bind situations, which are a problem for the citizen, the public servant and the welfare service system. NAV is concerned with solving this problem in a better way; however, this seems to be impossible without being able to disclose double bind functioning. 


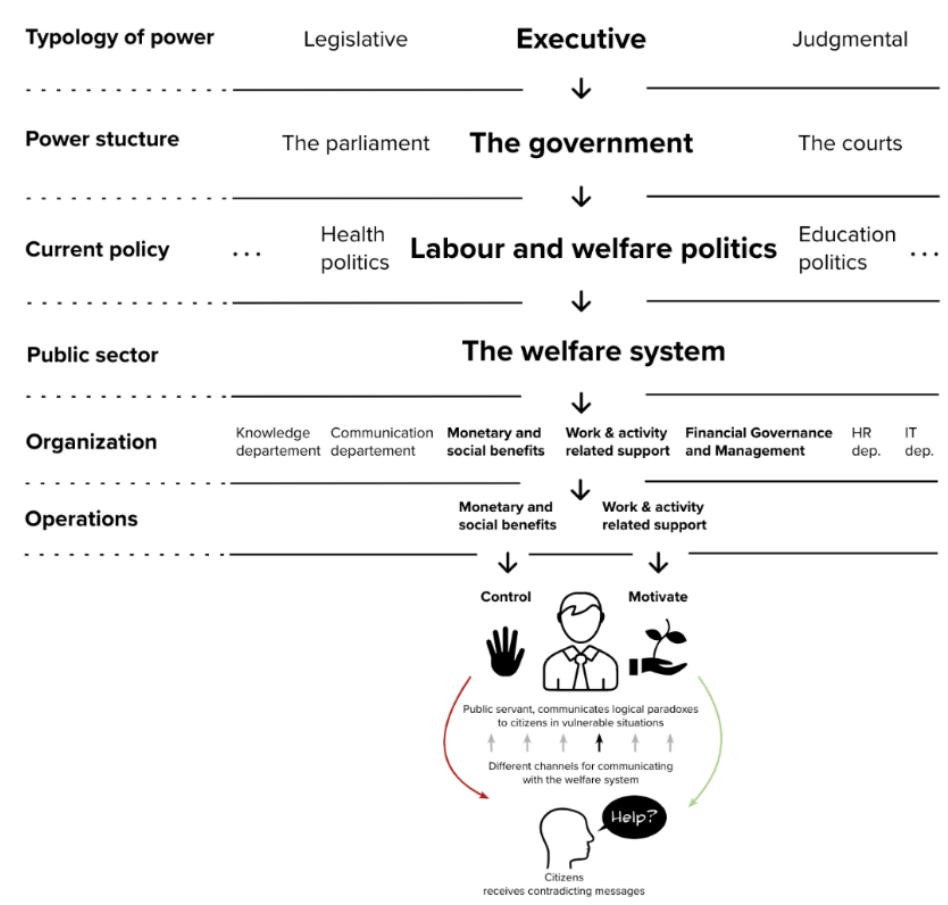

Figure 3. The model shows a praxis analysis of the communication between the citizen and NAV supervisor. The communication represents a double bind situation in which the supervisor promises aid if the citizen complies to be controlled. The double bind praxis is positioned by visualization within the structures for a welfare system. The designers may utilize such holistic practices to detect relevant structures, information flows and other dynamics relevant for communication systems and thus double bind functioning on different levels

A systemic design approach seeks to understand organizations and services holistically and to reveal their systemic character and functioning. The outset is to understand encounters, interactions, and communication between citizens and public servants, which are often described as dysfunctional conversations and exchange of information. The double bind communication in these encounters can lead to the cementation of a citizen's troublesome situation. Due to the control function, the public servant must execute and force the citizen to document his or her illness or otherwise problematic life events in exchange for welfare support. However, if not detected and designed consciously, the double bind functioning of these services may even be destructive for the person seeking help. We, therefore, suggest that the model of logical paradoxes is utilized in design education to help future designers handle such complex issues.

\section{REFERENCES}

[1] Bateson M. C. The Double Bind: Pathology and Creativity. Cybernetics \& Human Knowing. 2005;12(f0020001):11-21.

[2] Bateson G. Steps to an ecology of mind. Chicago: University of Chicago Press; 2000/1972.

[3] Forrester J. W. Counterintuitive behavior of social systems. Technological Forecasting \& Social Change. 1971;3:1-22.

[4] Ashby W. R. An Introduction to Cybernetics. 1963.

[5] Meadows D. Leverage Points: Places to Intervene in a System. Hartland. VT. USA; 1999. 